CENTRE FOR EMEA BANKING, FINANCE \& ECONOMICS

\title{
THE WEEKLY STRUCTURE OF US STOCK PRICES
}

Guglielmo Maria Caporale and Luis A. Gil-Alana

Working Paper Series

$$
\text { No 10/11 }
$$




\title{
THE WEEKLY STRUCTURE OF US STOCK PRICES
}

\author{
Guglielmo Maria Caporale \\ Brunel University, London
}

and

\author{
Luis A. Gil-Alana* \\ University of Navarra
}

\begin{abstract}
In this paper we use fractional integration techniques to examine the degree of integration of four US stock market indices, namely the Standard and Poor, Dow Jones, Nasdaq and NYSE, at a daily frequency from January 2005 till December 2009. We analyse the weekly structure of the series and investigate their characteristics depending on the specific day of the week. The results indicate that the four series are highly persistent; a small degree of mean reversion (i.e., orders of integration strictly smaller than 1) is found in some cases for S\&P and the Dow Jones indices. The most interesting findings are the differences in the degree of dependence for different days of the week. Specifically, lower orders of integration are systematically observed for Mondays and Fridays, consistently with the "day of the week" effect frequently found in financial data.
\end{abstract}

Keywords: Fractional Integration, Weekly Structure, Stock Prices

JEL Classification: C22, G12

Corresponding author: Professor Guglielmo Maria Caporale, Centre for Empirical Finance, Brunel University, West London, UB8 3PH, UK. Tel.: +44 (0)1895 266713. Fax: +44 (0)1895 269770. Email: Guglielmo-Maria.Caporale@brunel.ac.uk

The second-named author gratefully acknowledges financial support from the the Ministerio de Ciencia y Tecnología (ECO2008-03035 ECON Y FINANZAS, Spain) and from a PIUNA Project from the University of Navarra. 


\section{Introduction}

Determining the correct order of integration of stock prices is still an unresolved issue. While the efficiency market hypothesis suggests that they should follow a random walk (see Fama, 1970; Summers, 1986), other studies have found evidence of mean reversion in their behaviour (see, e.g., Poterba and Summers, 1988 and Fama and French, 1988). Most authors assume that (log-)prices are $\mathrm{I}(1)$, i.e. that stock returns are stationary $\mathrm{I}(0)$. The key question is then whether shocks are autocorrelated, with would imply that markets are not efficient, as pointed out by Caporale and Gil-Alana (2002). That study also stresses that the unit root tests normally employed impose very restrictive assumptions on the behaviour of the series of interest, in addition to having low power. It is suggested instead that tests which allow for fractional alternatives should be used. This is important in order to determine if stock prices are mean-reverting or not even in non-stationary contexts, which is in fact a hotly debated topic in empirical finance. Lo and MacKinlay (1988) and Poterba and Summers (1988) used variance-ratio tests and found evidence of mean reversion in stock prices. On the contrary, Lo (1991) used a generalised form of rescaled range (R/S) statistic and found no evidence against the random walk hypothesis for the stock indices.

Long-memory specifications have been used for financial data by Crato (1994), Cheung and Lai (1995), Barkoulas and Baum (1996), Barkoulas, Baum, and Travlos (2000), Sadique and Silvapulle (2001), Henry (2002), Tolvi (2003) and Gil-Alana (2006) among others. Caporale and Gil-Alana (2007) decompose the stochastic process followed by US stock prices into a long-run component described by the fractional differencing parameter (d) and a short-run (ARMA) structure. Empirical support for non-linear asset pricing models (such as the one by Dittmar, 2002) has also been found (see, inter alia, Hossein and Sonnie, 2008). 
In this paper we first use fractional integration techniques to estimate the degree of integration of the following four stock market indices: Standard and Poor, Dow Jones, Nasdaq and NYSE, at a daily frequency, over the sample period January $3^{\text {rd }}, 2005$ December $3^{\text {rd }}, 2009$. We also examine their weekly structure and characteristics depending on the specific day of the week.

Calendar effects (such as the weekend effect, the day of the week effect, and the January effect) in financial series, both in the US and in other developed markets, have been reported in many studies starting with Osborne (1962). Negative Monday returns were found, inter alia, by Cross (1973), French (1980), and Gibbons and Hess (1981), the former two analysing the S\&P 500 index, the latter the Dow Jones Industrial Index. Similar findings have been reported for other US financial markets, such as the futures, bond and Treasury bill markets (Cornell, 1985, Dyl and Maberly, 1986), foreign exchange markets (Hsieh, 1988), and for Australian, Canadian, Japanese and UK financial markets (e.g., Jaffe and Westerfield, 1985, Jaffe, Westerfield and Ma, 1989, Agrawal and Tandon, 1994). Effects on stock market volatility have also been documented (Kiymaz and Berument, 2003).

Various explanations have been offered for the observed patterns. Some focus on delays between trading and settlement in stocks (Gibbons and Hess, 1981): buying on Fridays creates a two-day interest-free loan until settlement; hence, there are higher transaction volumes on Fridays, resulting in higher prices, which decline over the weekend as this incentive disappears. Others emphasise a shift in the broker-investor balance in buying-selling decisions which occurs at weekends, when investors have more time to study the market themselves (rather than rely on brokers); this typically results in net sales on Mondays, when liquidity is low in the absence of institutional trading (Miller, 1988). It has also been suggested that the Monday effect largely reflects the fact that, when daily returns are calculated, the clustering of dividend payments around Mondays is normally ignored; alternatively, it could be a consequence of positive news typically being released during the week, and negative ones over the weekend (Fortune, 1998). Additional 
factors which could be relevant are serial correlation, with Monday prices being affected by Friday ones, and a negative stock performance on Fridays being given more weight (Abraham and Ikenberry, 1994); measurement errors (Keim and Stambaugh, 1984); size (Fama and French, 1992); volume (Lakonishok and Maberly, 1990).

The present study is structured as follows: Section 2 briefly outlines the methodology employed. Section 3 describes the data. Section 4 reports the empirical results, while Section 5 contains some concluding comments.

\section{Methodology}

Given a zero-mean covariance stationary process $\left\{x_{t}, t=0, \pm 1, \ldots\right\}$ with autocovariance function $\gamma_{u}=E\left(x_{t} x_{t+u}\right)$, the time domain definition of short memory or $\mathrm{I}(0)$ states that:

$$
\sum_{u=-\infty}^{\infty}\left|\gamma_{u}\right|<\infty
$$

Now, assuming that $x_{t}$ has an absolutely continuous spectral distribution, so that it has spectral density function

$$
f(\lambda)=\frac{1}{2 \pi}\left(\gamma_{0}+2 \sum_{u=1}^{\infty} \gamma_{u} \cos (\lambda u)\right)
$$

according to the frequency domain definition of short memory the spectral density function should be bounded and positive at all frequencies in the spectrum. These definitions include a wide variety of model specifications, such as white noise, stationary autoregression (AR), moving average (MA), stationary ARMA, etc.

In the above context, one can say that a process is integrated of order $\mathrm{d}$, and denoted by $I(d)$, if after taking d differences the process becomes $I(0)$. In other words, $x_{t}$ is $I(d)$ if:

$$
\begin{aligned}
& (1-L)^{d} x_{t}=u_{t}, \quad t=0, \pm 1, \ldots, \\
& x_{t}=0, \quad t \leq 0,
\end{aligned}
$$


with $\mathrm{d}>0$, where $L$ is the lag-operator $\left(L x_{t}=x_{t-1}\right)$ and $u_{t}$ is $I(0)$. Clearly, if $\mathrm{u}_{\mathrm{t}}$ is $\operatorname{ARMA}(\mathrm{p}$, $q)$, then $x_{t}$ is said to be $\operatorname{ARFIMA}(p, d, q)$. In this context, if $d=0, x_{t}$ is stationary $I(0)$ and is commonly characterised as "short memory"; on the contrary, if $\mathrm{d}>0, \mathrm{x}_{\mathrm{t}}$ is said to be "long memory", so-named because of the strong degree of association between observations far distant in time; if $\mathrm{d}$ belongs to the interval $(0,0.5)$ the series is still covariance stationary but the autocorrelations take a longer time to disappear than in the $I(0)$ case. ${ }^{1}$ If $d$ is in the interval $[0.5,1)$ the series is no longer stationary; however, it is still mean-reverting in the sense that shocks affecting the series disappear in the long run. Finally, if $d \geq 1$ the series is non-stationary and non-mean-reverting. The $\mathrm{I}(\mathrm{d})$ processes (with $\mathrm{d}>0$ ) were introduced by Granger and Joyeux (1980), Granger (1980, 1981)) and Hosking (1981) and were justified in terms of aggregation by Robinson (1978) and Granger (1980). These authors showed that fractionally integration could arise as a result of aggregation. ${ }^{2}$ In the last fifteen years I(d) models have been widely employed to describe the behaviour of many macroeconomic and financial time series data (see, e.g., Diebold and Rudebusch, 1989; Sowell, 1992; Gil-Alana and Robinson, 1997; etc.).

The method employed in this paper is based on the Whittle function in the frequency domain (Dahlhaus, 1989) along with a testing procedure developed by Robinson (1994). The latter is a very general method that allows to test the null $H_{0}: d=d_{0}$ in (1) for any real value of $d_{0}$, thus including stationary $\left(d_{0}<0.5\right)$ and non-stationary $\left(d_{0} \geq 0.5\right)$ hypotheses.

\section{The dataset}

The series used for the analysis are the following four indices: S\&P Composite 1500; the NASDAQ Composite IXIC; the New York Stock Exchange (NYSE) Composite Index; and

\footnotetext{
${ }^{1}$ More precisely, the autocorrelations decay at a hyperbolical rate (slowly), unlike in the I(0) (AR) case where the rate of decay is exponential (rapid).

${ }^{2}$ They showed that fractional integration could result from aggregation across heterogeneous autoregressive (AR) processes.
} 
the Dow Jones Composite Average (DJA) index. The samples begin on January $3^{\text {rd }}, 2005$ and end on December $31^{\text {st }}, 2009$. In all cases, if there is no value for a given day, the arithmetic mean using the previous and the following observation was computed.

\section{[Insert Figure 1 about here]}

The four log-prices series and their corresponding returns are displayed in Figure 1. It can be seen that the four indices move in a very similar way, with a sharp decrease at the beginning of the sample and an increase from around 2006, with values decreasing slowly from mid-2007 till the end of the sample. Panel (b) in Figure 1 displays the return series, obtained as the first differences of the log prices. One can see that volatility has sharply increased in the last part of the sample in all cases. ${ }^{3}$

\section{Empirical results}

We consider first the following model,

$$
y_{t}=\alpha+x_{t}, \quad(1-L)^{d} x_{t}=u_{t}, \quad t=1,2, \ldots
$$

where $y_{t}$ is the observed time series, $x_{t}$ is assumed to be $I(d)$ and $u_{t}$ is the error term. We consider the cases of white noise, $\mathrm{AR}(1)$ and Bloomfield-type disturbances. The latter is a non-parametric specification, due to Bloomfield (1973), that produces autocorrelations decaying exponentially as in the $\mathrm{AR}(\mathrm{MA})$ case. $^{4}$

\section{[Insert Table 1 about here]}

Table 1 reports the estimates of $d$ from model (1), as well as the $95 \%$ confidence bands corresponding to the non-rejection values of $d$ using Robinson's (1994) parametric approach. With white-noise disturbances, the estimated values of $d$ are strictly smaller than 1 for the four series, implying mean-reverting behaviour. If $u_{t}$ is $A R$, the values of $d$ are still smaller than 1 , but the unit root null hypothesis cannot be rejected in the cases of the Nasdaq and the NYSE indices. When using

\footnotetext{
${ }^{3}$ Note, however, that the present paper does not focus on volatility. Also, the analysis is based on methods that are robust to the presence of conditional heteroscedastic errors.

${ }^{4}$ See Gil-Alana (2004) for a study with Bloomfield disturbances in the context of Robinson's (1994) tests.
} 
the more general Bloomfield specification, the unit root cannot be rejected for any of the series. Thus, the results change substantially depending on the specification of the error term. For this reason, we also employ a semi-parametric method suggested by Robinson (1995). This is based on the Whittle function in the frequency domain using a band of frequencies that degenerates to zero. The estimate of $d$ is implicitly defined by:

$$
\begin{gathered}
\hat{d}=\arg \min _{d}\left(\log \overline{C(d)}-2 d \frac{1}{m} \sum_{s=1}^{m} \log \lambda_{s}\right), \\
\overline{C(d)}=\frac{1}{m} \sum_{s=1}^{m} I\left(\lambda_{s}\right) \lambda_{s}^{2 d}, \quad \lambda_{s}=\frac{2 \pi s}{T}, \quad \frac{m}{T} \rightarrow 0,
\end{gathered}
$$

where $\mathrm{m}$ is a bandwidth number, and $\mathrm{I}\left(\lambda_{\mathrm{s}}\right)$ is the periodogram of the raw time series, $\mathrm{x}_{\mathrm{t}}$,

$$
I\left(\lambda_{s}\right)=\frac{1}{2 \pi T}\left|\sum_{t=1}^{T} x_{t} e^{i \lambda_{s} t}\right|^{2},
$$

and $d \in(-0.5,0.5)$.

Given the non-stationary nature of the series the analysis is conducted on the first differenced data, then adding 1 to the estimated value of $d$. The results for the whole range of values of the bandwidth parameter (displayed on the horizontal axis) are shown in Figure $2 .^{5}$

\section{[Insert Figure 2 about here]}

It can be seen that, when the bandwidth parameter is low, most estimates are within the I(1) interval. However, increasing m leads to estimated values of $\mathrm{d}$ strictly below this interval. Note that the choice of $\mathrm{m}$ is crucial in terms of the trade-off between bias and variance. The asymptotic variance of this estimator is decreasing with $\mathrm{m}$ while the bias is growing with $\mathrm{m}$. However, the optimal choice of the bandwidth parameter in the context of the Whittle function has yet to be theoretically established. When using $\mathrm{m}=(\mathrm{T})^{1 / 2}$ the

\footnotetext{
${ }^{5}$ Some methods to calculate the optimal bandwidth parameters in semiparametric contexts have been examined in Delgado and Robinson (1996) and Robinson and Henry (1996). However, in the case of the Whittle estimator of Robinson (1995), the use of optimal values has not been theoretically justified. Other authors, such as Lobato and Savin (1998), use values for $\mathrm{m}$ within a short interval, whilst here we report the results for a wide range of values of $m$.
} 
estimates are 1.071 for the Dow Jones; 1.135 for the Nasdaq; 1.163 for NYSE and 1.145 for S\&P, and the unit root null cannot be rejected in any of the four series.

In what follows we focus on individual days of the week for each stock index. Tables 2 - 5 report the estimates of $d$ (and the 95\% confidence bands) for each day of the week and each series, using again the three types of disturbances as in Table 1.

\section{[Insert Tables 2 - 5 about here]}

Table 2 concerns the S\&P index. Here the unit root null hypothesis cannot be rejected in any case. All the values are slightly above 1, with the exception of Monday and Friday in the case of white noise errors. Very similar results are obtained for the other three indices: the I(1) case cannot be rejected in any case; the estimated values of $d$ are above 1 in all cases with autocorrelated errors; if the error term is white noise, the estimated values are below 1 for all days except Wednesday for the Dow Jones (Table 3), and Monday in the case of the Nasdaq (Table 4) and the NYSE (Table 5). The result based on white noise errors is one of the interesting features observed in the data, since the lowest degrees of integration seem to occur at the beginning and end of the week (Mondays and Fridays) for the four indices (see Figure 3). When using the semi-parametric method of Robinson (1995) most of the estimates are within the I(1) interval, though again the lowest values of $\mathrm{d}$ correspond to Mondays and Fridays (Figure 4).

\section{[Insert Figures 3 and 4 about here]}

Given these weekly features in the data we finally consider a model that incorporates them in a long-memory framework. Thus, we consider the model,

$$
y_{t}=\alpha+x_{t}, \quad\left(1-L^{5}\right)^{d} x_{t}=u_{t}, \quad t=1,2, \ldots
$$

with white noise, AR and Bloomfield $u_{t}$ disturbances. The results based on the estimates of $d$ are reported in Table 6. It can be seen that the results are very similar for all series and 
regardless of the types of disturbances considered. All values are slightly below 1 and the unit root null cannot be rejected in any case.

\section{[Insert Table 6 about here]}

\section{Conclusions}

In this paper we have investigated the degree of integration in four US stock market indices, namely the Standard and Poor, Dow Jones, Nasdaq and NYSE, using long range dependence techniques. We used daily data from January 3, 2005 till December 31, 2009. The results indicate that the four series are highly persistent; a small degree of mean reversion (i.e., orders of integration strictly smaller than 1) is found in some cases for the S\&P and the Dow Jones indices. The most interesting findings are the differences in the degree of dependence for different days of the week. Specifically, lower orders of integration are systematically observed for Mondays and Fridays, consistently with the "day of the week" effect frequently found in financial data (Cross, 1973; French, 1980; Gibbons and Hess, 1981; etc.). Even when using a long-memory model that incorporates such weekly effects, the unit root null hypothesis cannot be rejected, and therefore there is no evidence of mean reversion in the behaviour of stock prices. 


\section{References}

Abraham, A. and D. Ikenberry, 1994, The individual investor and the weekend effect, Journal of Financial and Quantitative Analysis 29, June, 263-277.

Agrawal, A. and K. Tandon, 1994, Anomalies or illusions? Evidence from stock markets in eighteen countries, Journal of International Money and Finance 13, 83-106.

Barkoulas, J.T. and C.F. Baum, 1996, Long term dependence in stock returns. Economics Letters 53, 253-259.

Barkoulas, J.T., C.F. Baum and N. Travlos, 2000, Long memory in the Greek stock market. Applied Financial Economics 10, 177-184.

Bloomfield, P. (1973) An exponential model in the spectrum of a scalar time series. Biometrika 60, 217-226.

Caporale, G.M. and L.A. Gil-Alana, 2002, Fractional integration and mean reversion in stock prices, Quarterly Review of Economics and Finance 42, 599-609.

Caporale, G.M. and L.A. Gil-Alana, 2007, Long run and cyclical dynamics in the US stock market, CESifo Working Paper no. 2046.

Cheung, Y.- W. and K.S. Lai, 1995, A search for long memory in international stock market returns. Journal of International Money and Finance 14, 597-615.

Cornell, B., 1985, The weekly patterns in stock returns cash versus futures: A note, Journal of Finance, 40, 583-588.

Crato, N., 1994, Some international evidence regarding the stochastic behaviour of stock returns. Applied Financial Economics 4, 33-39.

Cross, F., 1973, The behavior of stock prices on Fridays and Mondays, Financial Analyst Journal, 29, (November-December), 67-69.

Dahlhaus, R. (1989) Efficient parameter estimation for self-similar process. Annals of Statistics 17, 1749-1766. 
Delgado, M.A. and P.M. Robinson, 1996, Optimal spectral bandwidth for long memory. Statistica Seneca, 6, 97-112.

Diebold, F.X. and G.D. Rudebusch (1989) Long memory and persistence in the aggregate output. Journal of Monetary Economics 24, 189-209.

Dittmar, R.F., 2002, Nonlinear Pricing Kernels, Kurtosis Preference, and Evidence from the Cross Section of Equity Returns, Journal of Finance, American Finance Association, vol. 57(1), 369-403.

Dyl, E. and E.D. Maberly, 1986, The anomaly that isn't there: A comment on Friday the thirteenth, Journal of Finance 43, 1285-1286.

Fama, E.F., 1970, Efficient capital markets: a review of theory and empirical work, Journal of Finance $25,383-417$.

Fama, E.F. and K.R. French, 1988, Permanent and transitory components of stock prices, Journal of Political Economy 96, 246-273.

Fama, E. and K. French, 1992, The cross-section of expected stock returns, Journal of Finance 47, June, 427-465.

Fortune, P., 1998, Weekends can be rough: revisiting the weekend effect in stock prices, Working Paper no. 98-6, Federal Reserve Bank of Boston.

French, K., 1980, Stock returns and the weekend effect, Journal of Financial Economics 8, 55-69.

Gibbons, M. and P. Hess, 1981, Day of the week effects and asset returns, Journal of Business 54, 579-596.

Gil-Alana, L.A (2004) The use of the model of Bloomfield as an approximation to ARMA processes in the context of fractional integration, Mathematical and Computer Modelling 39, 429-436.

Gil-Alana, L.A., 2006, Fractional integration in daily stock market returns. Review of Financial Economics 15, 28-48.

Gil-Alana, L.A. and P.M. Robinson (1997) Testing of unit roots and other nonstationary hypotheses in macroeconomic time series. Journal of Econometrics 80, 241-268. 
Granger, C.W.J. (1980) Long memory relationships and the aggregation of dynamic models. Journal of Econometrics 14, 227-238.

Granger, C.W.J. (1981) Some properties of time series data and their use in econometric model specification. Journal of Econometrics 16, 121-130.

Granger, C.W.J. and R. Joyeux (1980) An introduction to long memory time series and fractionally differencing. Journal of Time Series Analysis 1, 15-29.

Henry, O.T., 2002, Long memory in stock returns. Some international evidence. Applied Financial Economics 12, 725-729.

Hosking, J.R.M. (1981) Fractional differencing. Biometrika 68, 165-176.

Hossein, A. and K. Sonnie, 2008, Evaluating a nonlinear asset pricing model on international data, International Review of Financial Analysis 17, 3, 604-621.

Hsieh, D.A., 1988, The statistical properties of daily foreign exchange markets: 1974-1983, Journal of International Economics 24, 129-145.

Jaffe, J.F. and R. Westerfield, 1985, The week-end effect in common stock reutrns. The international evidence, Journal of Finance 40, 433-454.

Jaffe, J.F., Westerfield, R. and C. Ma, 1989, A twist on the Monday effect in stock prices: Evidence from the US and foreign stock markets, Journal of Banking and Finance 13, 641-650.

Keim, D.B. and F. Stambaugh, 1984, A further investigation of weekend effects in sotck returns, Journal of Finance 39, 819-840.

Kiymaz, H. and H. Berument, 2003, The day of the week effect on stock market volatility and volume: international evidence, Review of Financial Economics 12, 4, 363-380.

Lakonishok, J. and E. Maberly, 1990, The weekend effect: trading patterns of individual and institutional investors, Journal of Finance 45, 1 (March), 231-244.

Lo, A., 1991, Long term memory in stock prices, Econometrica 59, 1279-1313.

Lo, A, and A.C. MacKinlay, 1988, Stock prices do not follow a random walk. Evidence from a simple specification test, Review of Financial Studies 1, 41-66. 
Lobato, I.N. and N.E. Savin, 1998, Real and spurious long memory properties of stock market data. Journal of Business and Economic Statistics 16, 261-283.

Miller, E., 1988, Why a weekend effect?, Journal of Portfolio Management 14, Summer, 42-48.

Osborne, M.F.M., 1962, Periodic structure in the Brownian motion of the stock market, Operations Research 10, 345-379.

Poterba, J. and L. Summers, 1988, Mean reversion in stock returns. Evidence and implications, Journal of Financial Economics 22, 27-60.

Robinson, P.M. (1978) Statistical inference for a random coefficient autoregressive model. Scandinavian Journal of Statistics 5, 163-168.

Robinson, P.M. (1994) Efficient tests of nonstationary hypotheses. Journal of the American Statistical Association 89, 1420-1437.

Robinson, P.M., 1995, Gaussian semiparametric estimation of long range dependence, Annals of Statistics 23, 1630-1661.

Robinson, P.M. and M. Henry, 1996, Bandwidth choice in Gaussian semiparametric estimation of long-range dependence, P.M. Robinson and M. Rosenblatt eds. Athens Conference on Applied Probability in Time Series Analysis, Vol.II, New York, 220-232. Sadique, S. and P. Silvapulle, 2001, Long-term memory in stock market returns. International evidence. International Journal of Finance and Economics 6, 59-67.

Sowell, F. (1992) Modelling long run behaviour with the fractional ARIMA model. Journal of Monetary Economics 29, 277-302.

Summers, L.H., 1986, Does the stock market rationally reflect fundamental values?, Journal of Finance 41, 591-601.

Tolvi, J., 2003, Long memory and outliers in stock market returns. Applied Financial Economics 13, 495-502. 
Figure 1: Log-prices series and their corresponding returns

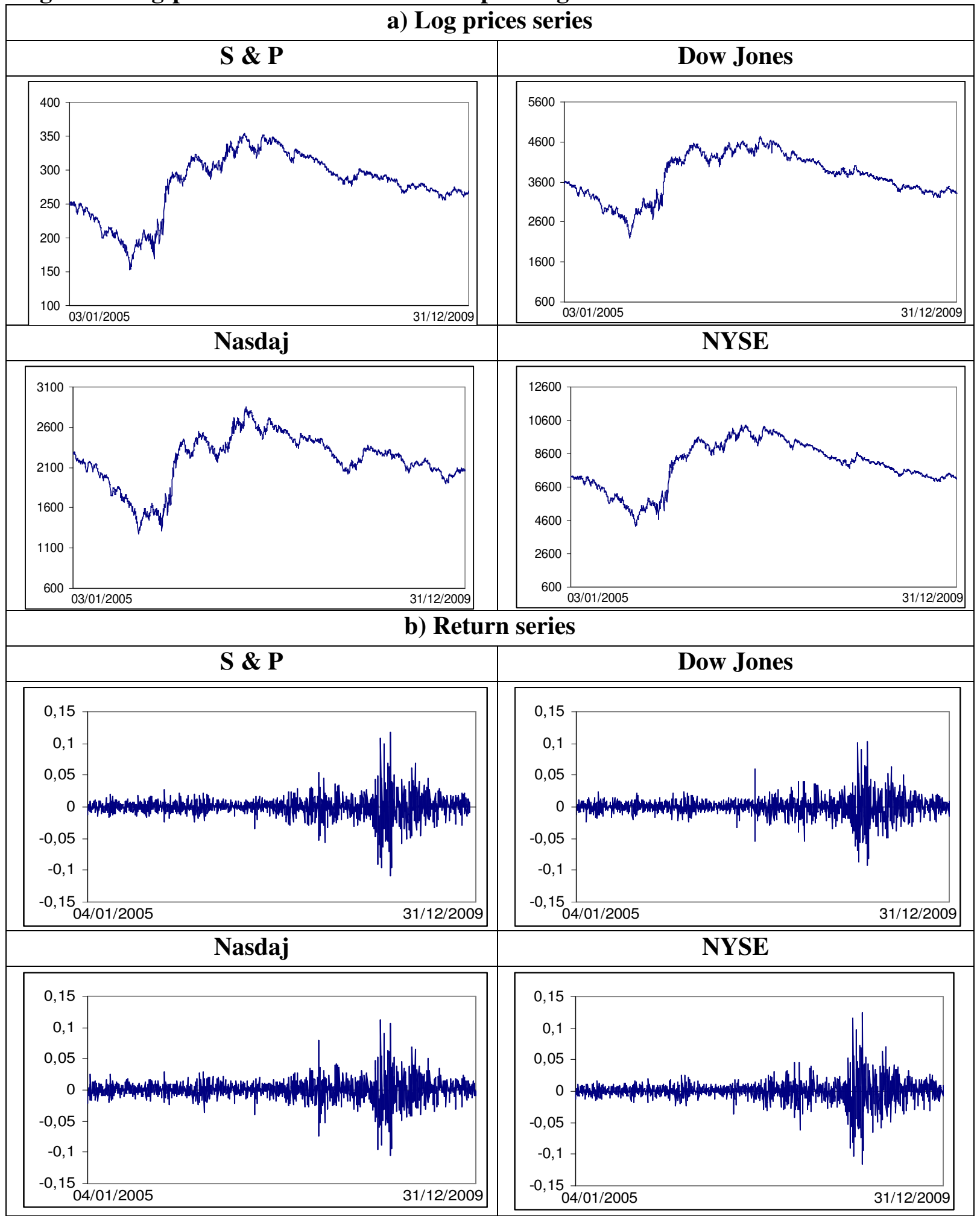

The returns were calculated as the first differences of the log-prices series. 
Table 1: Estimates of the differencing parameter in the logged time series

\begin{tabular}{|c|c|c|c|}
\hline & White noise & AR (1) & Bloomfield (1) \\
\hline \multirow{2}{*}{ S \& P } & 0.858 & 0.955 & 0.983 \\
& $(0.837,0.884)$ & $(0.921,0.995)$ & $(0.943,1.033)$ \\
\hline \multirow{2}{*}{ Dow Jones } & 0.867 & 0.951 & 0.973 \\
& $(0.844,0.893)$ & $(0.915,0.992)$ & $(0.933,1.030)$ \\
\hline \multirow{2}{*}{ Nasdaq } & 0.877 & 0.971 & 0.995 \\
& $(0.855,0.904)$ & $(0.935,1.012)$ & $(0.950,1.046)$ \\
\hline \multirow{2}{*}{ NYSE } & 0.878 & 0.964 & 0.982 \\
& $(0.856,0.904)$ & $(0, .928,1.003)$ & $(0.943,1.031)$ \\
\hline
\end{tabular}

The reported values are Whittle estimates of $d$ in the frequency domain. Those in parentheses refer to the $95 \%$ confidence intervals for the non-rejection values of $d$ using Robinson's (1994) tests.

Figure 1: Estimates of $d$ based on the semiparametric Whittle method (Robinson, 1995)

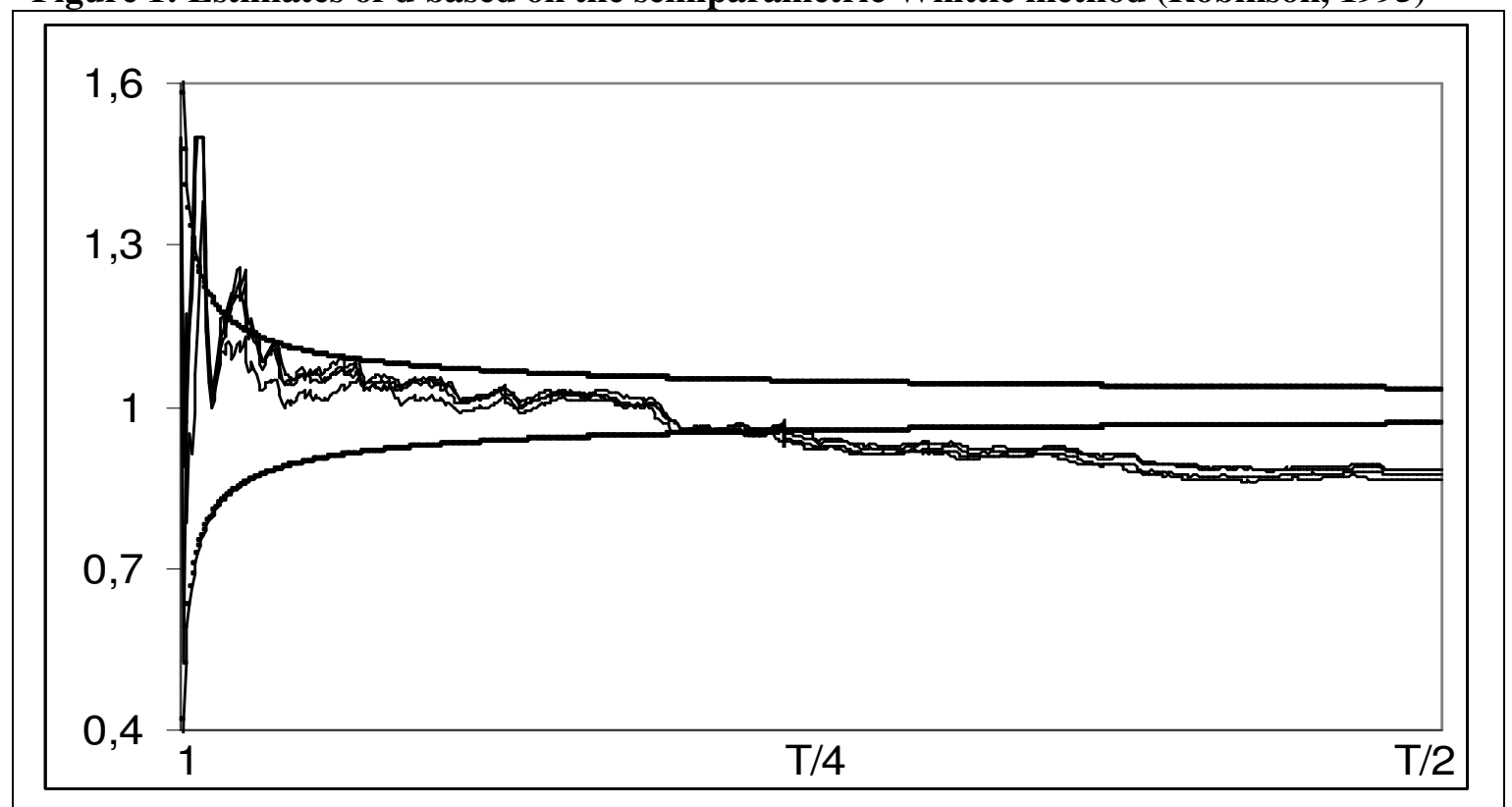

The horizontal axis refers to the bandwidth parameter, while the vertical one reports the estimated value of $d$. 
Table 2 Estimates of the fractional differencing parameter in the logged time series

\begin{tabular}{|c|c|c|c|}
\hline S \& P & White noise & AR (1) & Bloomfield (1) \\
\hline Monday & 0.969 & 1.069 & 1.098 \\
& $(0.912,1.052)$ & $(0.975,1.188)$ & $(0.980,1.248)$ \\
\hline \multirow{2}{*}{ Tuesday } & 1.014 & 1.077 & 1.092 \\
\hline Wednesday & $(0.956,1.090)$ & $(0.987,1.189)$ & $(0.990,1.233)$ \\
\hline \multirow{2}{*}{ Thursday } & 1.024 & 1.021 & 1.018 \\
\hline \multirow{2}{*}{ Friday } & $(0.961,1.108)$ & $(0.932,1.130)$ & $(0.921,1.153)$ \\
\hline
\end{tabular}

The reported values are Whittle estimates of $d$ in the frequency domain. Those in parentheses refer to the 95\% confidence intervals for the non-rejection values of $d$ using Robinson's (1994) tests.

Table 3: Estimates of the fractional differencing parameter in the logged time series

\begin{tabular}{|c|c|c|c|}
\hline Dow Jones & White noise & AR $(1)$ & Bloomfield (1) \\
\hline \multirow{2}{*}{ Monday } & 0.940 & 1.035 & 1.049 \\
& $(0.884,1.012)$ & $(0.943,1.155)$ & $(0.951,1.196)$ \\
\hline \multirow{2}{*}{ Tuesday } & 0.996 & 1.037 & 1.044 \\
Wednesday & $(0.937,1.074)$ & $(0.947,1.151)$ & $(0.949,1.177)$ \\
\hline \multirow{2}{*}{ Thursday } & 1.007 & 0.997 & 0.995 \\
& $(0.943,1.092)$ & $(0.909,1.106)$ & $(0.904,1.117)$ \\
\hline \multirow{2}{*}{ Friday } & 0.989 & 1.036 & 1.035 \\
& $(0.925,1.073)$ & $(0.921,1.200)$ & $(0.927,1.175)$ \\
\hline
\end{tabular}

The reported values are Whittle estimates of $d$ in the frequency domain. Those in parentheses refer to the $95 \%$ confidence intervals for the non-rejection values of $d$ using Robinson's (1994) tests. 
Table 4: Estimates of the fractional differencing parameter in the logged time series

\begin{tabular}{|c|c|c|c|}
\hline Nasdaq & White noise & AR $(1)$ & Bloomfield (1) \\
\hline Monday & 0.968 & 1.064 & 1.100 \\
Tuesday & $(0.909,1.043)$ & $(0.966,1.181)$ & $(0.974,1.256)$ \\
\hline \multirow{2}{*}{ Wednesday } & 1.031 & 1.078 & 1.087 \\
\hline Thursday & $(0.968,1.112)$ & $(0.974,1.201)$ & $(0.970,1.239)$ \\
\hline Friday & $(0.972,1.122)$ & $(0.942,1.168)$ & $(0.940,1.198)$ \\
\hline
\end{tabular}

The reported values are Whittle estimates of $d$ in the frequency domain. Those in parentheses refer to the $95 \%$ confidence intervals for the non-rejection values of $d$ using Robinson's (1994) tests.

Table 5: Estimates of the fractional differencing parameter in the logged time series

\begin{tabular}{|c|c|c|c|}
\hline NYSE & White noise & AR $(1)$ & Bloomfield (1) \\
\hline Monday & 0.967 & 1.068 & 1.104 \\
& $(0.912,1.036)$ & $(0.982,1.176)$ & $(0.989,1.256)$ \\
\hline Tuesday & 1.014 & 1.084 & 1.108 \\
\hline Wednesday & $(0.958,1.087)$ & $(0.999,1.189)$ & $(1.002,1.255)$ \\
\hline Thursday & 1.024 & 1.030 & 1.035 \\
\hline \multirow{2}{*}{ Friday } & $(0.963,1.105)$ & $(0.947,1.133)$ & $(0.939,1.162)$ \\
\hline
\end{tabular}

The reported values are Whittle estimates of $d$ in the frequency domain. Those in parentheses refer to the 95\% confidence intervals for the non-rejection values of $d$ using Robinson's (1994) tests. 
Figure 3: Estimates of the differencing parameter for each day of the week

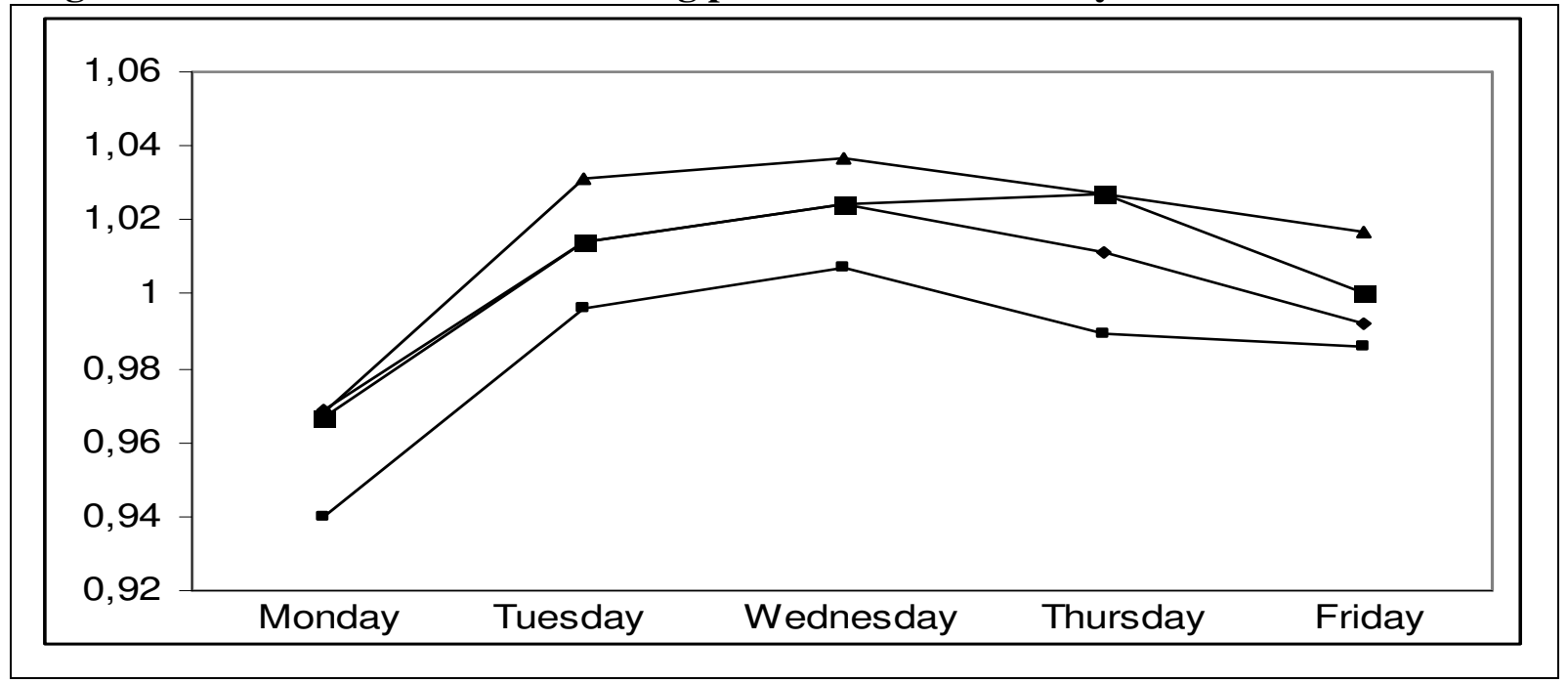

Figure 4: Estimates of $d$ based on the semiparametric Whittle method (Robinson, 1995) for the $S \& P$

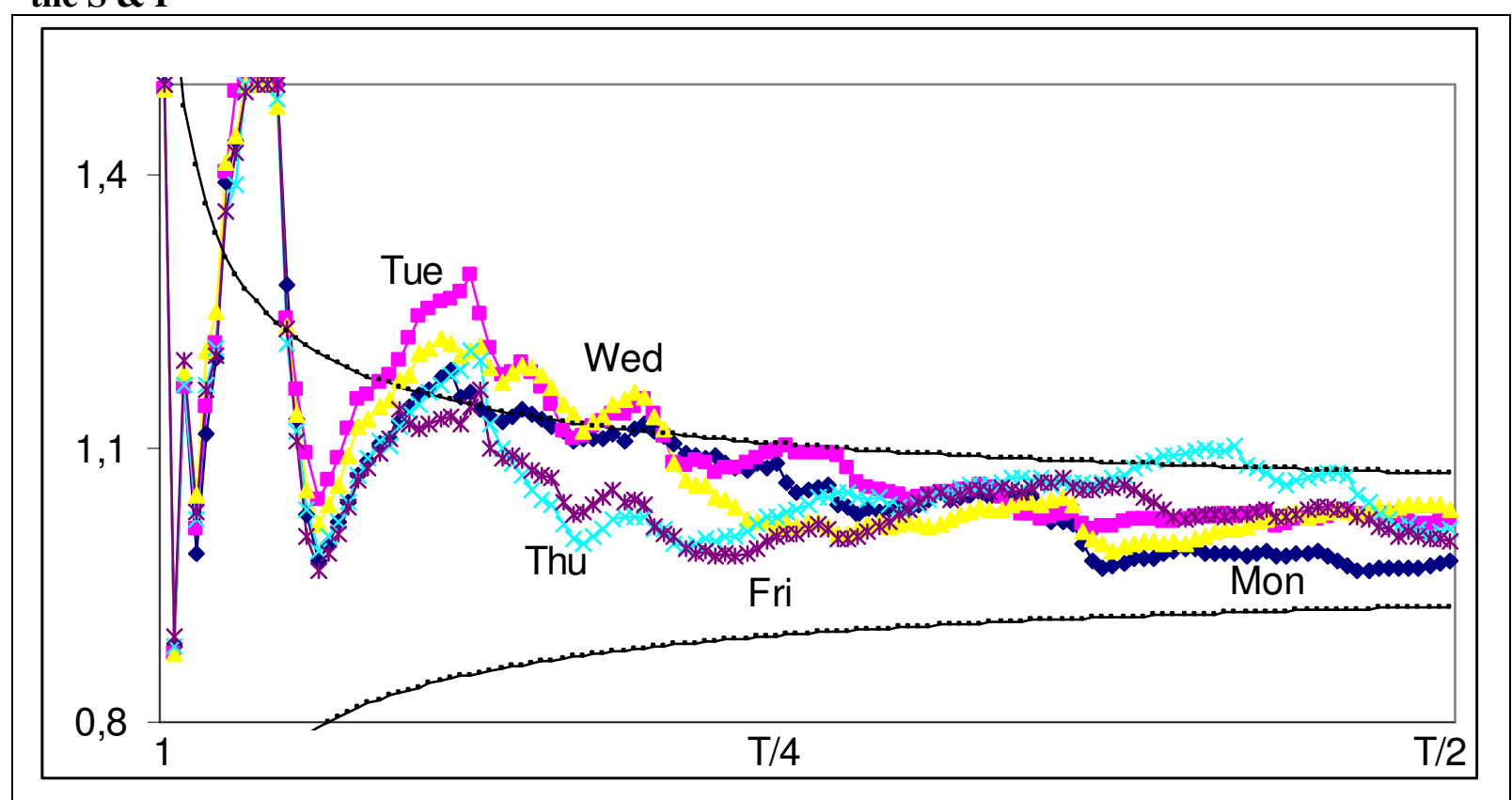

The horizontal axis refers to the bandwidth parameter, while the vertical one reports the estimated value of $d$. 
Table 6: Estimates of the $\left(1-\mathrm{L}^{5}\right)^{\mathrm{d}}$ differencing parameter in the log time series

\begin{tabular}{|c|c|c|c|}
\hline & White noise & AR (1) & Bloomfield (1) \\
\hline \multirow{2}{*}{ S \& P } & 0.983 & 0.987 & 0.983 \\
& $(0.944,1.027)$ & $(0.955,1.023)$ & $(0.948,1.028)$ \\
\hline \multirow{2}{*}{ Dow Jones } & 0.983 & 0.986 & 0.980 \\
& $(0.945,1.027)$ & $(0.954,1.022)$ & $(0.948,1.029)$ \\
\hline \multirow{2}{*}{ Nasdaq } & 0.983 & 0.987 & 0.983 \\
& $(0.944,1.027)$ & $(0.955,1.023)$ & $(0.946,1.027)$ \\
\hline \multirow{2}{*}{ NYSE } & 0.983 & 0.987 & 0.983 \\
& $(0.945,1.027)$ & $(0.955,1.023)$ & $(0.947,1.027)$ \\
\hline
\end{tabular}

The reported values are Whittle estimates of $d$ in the frequency domain. Those in parentheses refer to the $95 \%$ confidence intervals for the non-rejection values of d using Robinson's (1994) tests. 